\title{
TOLERABILITY OF RACECADOTRIL IN ACUTE WATERY DIARRHOEA IN CHILDREN
}

\author{
Maha Singh ${ }^{1}$, Alka Yadav², Sanjeev Nanda ${ }^{3}$
}

${ }^{1}$ Assistant Professor, Department of Paediatrics, SHKM Govt. Medical College, Nalhar (Mewat), Haryana.

${ }^{2}$ Assistant Professor, Department of Paediatrics, Pt. BD Sharma University of Health Sciences, Rohtak, Haryana.

${ }^{3}$ Senior Professor, Department of Paediatrics, Pt. BD Sharma University of Health Sciences, Rohtak, Haryana.

\section{ABSTRACT}

\section{BACKGROUND}

Acute diarrhoea remains a major cause of mortality and morbidity in children due to dehydration, dyselectrolytemia and nutrient loss. Racecadotril is found to be effective in reducing the stool output in acute watery diarrhoea in children through its potent antisecretory effect mediated by enkephalinase inhibition in basolateral membrane of enterocytes and promoting selective chloride absorption through delta receptors and may prove to be beneficial in complications associated with acute watery diarrhoea.

\section{AIMS}

To establish the safety profile and tolerability of racecadotril.

\section{STUDY DESIGN}

Present study is a placebo-controlled single blind prospective study.

\section{METHODOLOGY}

Study was conducted in 100 children aged 6 months to 5 years having acute watery diarrhoea with some dehydration. Inclusion and exclusion criteria were strictly adhered to throughout the study. Study cohort was divided into two groups. Group A received racecadotril ( $1.5 \mathrm{mg} / \mathrm{kg}$ thrice a day for 5 days or till diarrhoea stopped, whichever came earlier) as adjuvant therapy to low osmolarity ORS, whereas group B received placebo and low osmolarity ORS. Variables studied were any adverse effect observed or reported by patients or parents, symptoms associated with diarrhoea such as anorexia, nausea, vomiting, abdominal pain and abdominal distension and any rebound effects after the drug was discontinued.

\section{RESULTS}

Both the groups were comparable clinically as well as epidemiologically. Nausea and/or vomiting was reported by 13 patients $(26 \%)$ in group A and 14 patients (28\%) in group B with a 'p' value $(>0.05)$. Abdominal distension was reported by 3 patients in each group. None of the patients had electrolyte imbalance in either groups during the study. Abdominal pain though mild was reported by 6 patients $(12 \%)$ in group A and by 5 patients $(10 \%)$ in group B. None of the patients or parent reported any undesirable side effect of drug in study group. On discontinuing racecadotril rebound constipation was observed in 3 patients (6\%) in group A, whereas it was observed in 2 patients $(4 \%)$ in group B with ' $p$ ' value $(>0.05)$.

\section{CONCLUSION}

Racecadotril is as tolerable as placebo and can be used as adjuvant therapy in acute watery diarrhoea in children.

\section{KEYWORDS}

Racecadotril, Acute Watery Diarrhoea, Enkephalinase Inhibitor.

HOW TO CITE THIS ARTICLE: Singh M, Yadav A, Nanda S. Tolerability of racecadotril in acute watery diarrhoea in children. J. Evolution Med. Dent. Sci. 2016;5(69):5015-5018, DOI: 10.14260/jemds/2016/1139

\section{INTRODUCTION}

Diarrhoea is the third most frequent illness seen in general practice globally with as many as four billion cases occurring each year. ${ }^{1}$ Estimated 1.8 billion episodes of diarrhoea occur each year and 3 million children under the age of 5 years die in developing countries. ${ }^{2}$ Overall, children are ill with diarrhoea for $10-20 \%$ of their first 3 years of life. In India during 2005, about 1.07 million cases of acute diarrhoea were reported. Prevalence of diarrhoeal episodes in India in children less than

Financial or Other, Competing Interest: None.

Submission 06-08-2016, Peer Review 17-08-2016,

Acceptance 20-08-2016, Published 29-08-2016.

Corresponding Author:

Dr. Maha Singh,

Assistant Professor

Department of Paediatrics,

SHKM Govt. Medical College,

Nalhar (Mewat), Haryana.

E-mail: doc.mahasingh@gmail.com

DOI: $10.14260 /$ jemds/2016/1139
3 years continues to be as high as 19 percent. $^{3}$ In health institutions, up to a one-third of total paediatric admissions are due to diarrhoeal diseases and up to $17 \%$ of all deaths in indoor paediatric patients are diarrhoea related. ${ }^{4}$ Diarrhoea is defined as passage of loose, liquid or watery stools at least three times in 24 hours. However, it is the recent change in the consistency of stools rather than the frequency that is more important. Another definition of diarrhoea is stool output more than $10 \mathrm{gm} / \mathrm{kg} / 24$ hours or more than adult limit of 200 gm/24 hours. Acute diarrhoea is defined as an episode of sudden onset diarrhoea, which usually lasts 3 to 7 days, but may last up to 14 days. ${ }^{5}$ In nearly $70-80 \%$ cases of acute diarrhoea, causative agents can be identified. 6

The rotavirus is the single most important cause of diarrhoea in infants and children. ${ }^{7}$ Most common bacterial causes of diarrhoea are Vibrio Cholerae 01, Salmonella, Shigella, Enterotoxigenic Escherichia coli and Campylobacter jejuni. Driving forces operative in diarrhoea are osmotic, secretory, exudative or motility disturbances. ${ }^{8}$ In almost all 
acute episodes of diarrhoeal episodes, driving force is predominantly secretory with contribution from exudative and motility forces. Infections with bacteria and viruses cause diarrhoea mainly through enterotoxins which activate secretory processes; cholera enterotoxin is the prototype toxin. ${ }^{9}$ The case fatality rate has been reported as $0.56 \%$ for acute watery diarrhoea, $4.3 \%$ for dysentery and $11.9 \%$ for non-dysenteric persistent diarrhoea in longitudinally followed cohort of children under 6 years of age in rural North India. ${ }^{10}$ Most of the deaths from acute infectious diarrhoea result from excessive fluid or electrolyte losses that result in dehydration and acidosis. ${ }^{11}$ So any drug preventing these complications would decrease mortality and morbidity resulting from acute watery diarrhoea. Loss of same volume of fluid in a child would result proportionately in more dehydration as compared to an adult as ratio of fluid lost to the total body fluid volume would be very high in a child.

So children are more prone to complications of fluid loss due to diarrhoea as compared to adults. In children this predisposition is further compounded by malnourishment, which affects roughly 27 percent of children in third world countries. ${ }^{12}$ ORS is the corner stone of treatment of diarrhoea as it corrects and prevents dehydration and reduces mortality. It has been seen in Kolkata that as many as 90-95 percent of all cases of cholera and acute diarrhoea can be treated by oral fluid alone.13 Oral fluid therapy is based on the observation that given orally glucose enhances intestinal absorption of salt and water and is capable of correcting the electrolyte and water deficit.14 Management of nutrition during acute diarrhoea is an integral part of management plan. A recent meta-analysis supports the view that probiotics can shorten the duration of acute diarrhoeal illness in children by one day. 15 Zinc supplementation for 10-14 days during an acute diarrhoeal episode reduces both duration and severity of diarrhoea and therefore is recommended by WHO and UNICEF. Antidiarrhoeal therapy consists mainly of two classes of antidiarrhoeal agents: antimotility agents and antisecretory agents. Antimotility agents such as loperamide and a diphenoxylate atropine combination act by reducing gut motility. ${ }^{16}$

These agents can lead to adverse effects such as constipation, abdominal pain and abdominal distension, so they are usually not recommended for use.17,18 Antisecretory agents have recently been tried in treatment of acute watery diarrhoea. Zaldaride maleate-a calmodulin inhibitor, racecadotril - an enkephalinase inhibitor, thiazolidinone drug like moietics - cystic fibrosis transmembrane regulator protein inhibitor, SP 303 - chloride channel blocker and bismuth salicylate are some of the antisecretory agents tested for clinically efficacy. Racecadotril is an oral enkephalinase inhibitor used in the treatment of acute diarrhoea. It prevents the degradation of endogenous opioids (Enkephalins), thereby reducing hypersecretion of water and electrolytes into intestinal lumen without contributing to intestinal transit time. ${ }^{19}$ Enkephalins are endogenous opiate substances, which is an important family of proabsorptive neurotransmitters in the enteric nervous system. Enkephalins are rapidly broken down by enzymatic activity of a membrane bound metalloproteinase enkephalinase. This enzyme is found in abundance in GIT and accounts for more than $85 \%$ of the hydrolysis of methionine and leucine enkephalins.

Any substance inhibiting enkephalinase would increase concentration of enkephalins and hence increase proabsorptive activity of enkephalins. Enkephalins appear to have their major effect through delta receptor activation that induces a selective increase in chloride absorption. Racecadotril has been shown to be effective in reducing by almost half the stool output in young children with acute diarrhoea by its antisecretory action. ${ }^{20}$ Other antisecretory and antimotility agents could not be used clinically because of their intolerability, so the present study was taken up to evaluate the safety profile of racecadotril in children so that the risk benefit ratio could be weighed.

\section{MATERIAL AND METHODS}

The present study, a case control single blind prospective study was carried out on 100 patients of acute watery diarrhoea of either sex in the age group of 6 months to 5 years who came to paediatric medicine outpatient department, indoor or emergency department of a tertiary medical institute of North India from August 2006 to August 2007. An informed written consent was taken from at least one of the parents/guardians of all the patients included in the study. Patients presenting with acute watery diarrhoea and having some dehydration were included in this study. Patients presenting with acute dysentery, acute watery diarrhoea with severe dehydration requiring intravenous fluids, persistent vomiting or abdominal distension, infants with septicaemia, malnourished children and patients who had already received treatment outside the institute for the current diarrhoeal episode were excluded from the study. The patients selected as per selection criteria were randomly divided into two groups (Group A and Group B). Group A received racecadotril along with oral rehydration solution and Group $B$ received oral rehydration solution and a placebo. Sachets of appropriate dosages appearing similar in shape, size and colour of packing of racecadotril and sucrose as placebo were prepared by pharmacists in the pharmacy of the institute.

Identity of both placebo and the drug was concealed from the patients. Only low osmolarity oral rehydration solution as advocated by WHO was given. No other antibiotic or antimotility drug was given during the course of study to either group. Oral rehydration solution was given after classifying the patients into with no dehydration, some dehydration or severe dehydration as per WHO plan. ${ }^{21}$ Racecadotril was given $1.5 \mathrm{mg} / \mathrm{kg}$ body weight, orally three times a day, for 5 days or until diarrhoea stopped whichever came first. Drug, placebo and low osmolarity WHO-ORS were made available from the hospital. Diarrhoea was considered to have stopped if patient passed two consecutive formed stools or had not passed stools for 12 hours. A detailed clinical history was recorded and a detailed physical examination was conducted to gather the baseline information and to decide whether patient qualified for the study or not. The history included duration, frequency, onset and progression of diarrhoea, presence of blood, mucous or pus in the stools and any treatment taken for the current episode. On examination general condition of patients, presence of signs of dehydration and abdominal girth of each patient was recorded. Complete general physical and systemic examinations were done to look for systemic complications. In anthropometry examination, weight and height were recorded. Routine and relevant special investigations were carried out in all the subjects. 


\section{Variables Evaluated during the Study}

Any undesirable side effects as observed or reported by patients or parents, associated symptoms of diarrhoea if any nausea, vomiting, anorexia, pain abdomen, abdominal distension and rebound effect after drug was discontinued were evaluated. These assessments were observed from initiation of study till the time of recovery or up to the end of 5 days' period, if the child had not recovered by that time. The results were analysed statistically using student's t-test. Null hypothesis was rejected with level of significance $<0.05$.

\section{RESULTS}

Both the groups were clinically and epidemiologically comparable. Associated symptoms were compared in two groups. In group A 13 patients (26\%) had nausea and/or vomiting and in group B 14 patients (28\%) suffered similar problems with a ' $p$ ' value $(>0.05)$, which is not statistically significant. Abdominal distension was reported by 3 patients in group $A$ and a similar number of 3 patients $(6 \%)$ in group $B$ had same complaints. Abdominal distension was not of much clinical significance in either group and resolved spontaneously. No electrolyte imbalance was observed. Abdominal pain though mild was reported by 6 patients (12\%) in group A and by 5 patients (10\%) in group B, which is again not statistically significant. Pain abdomen was for a short duration and did not require any intervention. None of patients or parents reported any undesirable side effect of drug in study group. It was observed during the study that on discontinuing racecadotril rebound constipation occurred in 3 patients $(6 \%)$ in group $A$, whereas it was observed in 2 patients $(4 \%)$ in group $B$ with ' $p$ ' value $(>0.05)$ and the difference was not significant statistically.

\begin{tabular}{|c|c|c|}
\hline Sex & $\begin{array}{c}\text { Group A } \\
\text { No. of Cases (\%) }\end{array}$ & $\begin{array}{c}\text { Group B } \\
\text { No. of Cases (\%) }\end{array}$ \\
\hline Male & $26(52 \%)$ & $26(52 \%)$ \\
\hline Female & $24(48 \%)$ & $24(48 \%)$ \\
\hline Mean weight & $10.62 \pm 3.18$ & $10.66 \pm 3.25$ \\
\hline $\begin{array}{c}\text { Mean age } \\
\text { (months) }\end{array}$ & $19.93 \pm 14.15$ & $19.47 \pm 16.49$ \\
\hline Range of age & $\begin{array}{c}6 \text { months }-5 \\
\text { years }\end{array}$ & $\begin{array}{c}6 \text { months }-5 \\
\text { years }\end{array}$ \\
\hline Mean height (cm) & $79.81 \pm 12.3$ & $78.25 \pm 13.4$ \\
\hline \multicolumn{2}{|c|}{ Table 1: Distribution of Sex, Age and Weight } \\
\hline
\end{tabular}

\begin{tabular}{|c|c|c|c|}
\hline Parameter & Group A & Group B & P value \\
\hline Side effects & & & \\
\hline Nausea/vomiting & $27(54 \%)$ & $14(28 \%)$ & $>0.05$ \\
\hline $\begin{array}{c}\text { Abdominal } \\
\text { distension }\end{array}$ & $3(6 \%)$ & $3(6 \%)$ & $>0.05$ \\
\hline Abdominal pain & $6(12 \%)$ & $5(10 \%)$ & $>0.05$ \\
\hline Rebound effects & $3(6 \%)$ & $2(4 \%)$ & $>0.05$ \\
\hline \multicolumn{4}{|c|}{ Table 2: Comparison of Associated Symptom in } \\
Group A and Group B \\
\hline
\end{tabular}

\section{DISCUSSION}

The present study was planned to look for the safety profile of racecadotril in management of patients of acute diarrhoea. In the present study, racecadotril was found to be as safe as placebo. None of the patients suffered any severe side effects warranting discontinuation of drug or withdrawal from the study. In a study by Hamza et $\mathrm{al}^{22}$ it was observed that racecadotril was as safe and tolerable as placebo and frequency of symptoms and signs was similar after 4 days of treatment. Baumer et $\mathrm{al}^{23}$ also conducted a study in an experimental model to study the antidiarrhoeal activity of racecadotril in cathartic induced secretory diarrhoea as well as in acute diarrhoea of presumed infections origin. There was no difference between racecadotril and placebo in respect of side effects, particularly constipation which often accompanied antidiarrhoeal activity of mu-opioid receptor antagonists. Cezard et $\mathrm{al}^{24}$ also compared in their study racecadotril with placebo in respect to efficacy and tolerability.

It was found that racecadotril was as tolerable as placebo with no significant side effects. In a large number of studies, racecadotril was compared with loperamide (an antimotility drug) and it was observed that racecadotril is well tolerated, safe and free from significant side effects. Wang et al 25 conducted a blind, randomised controlled study to compare racecadotril and loperamide in acute diarrhoea. It showed that racecadotril group had a higher incidence of itching as compared to loperamide ( $28.6 \%$ vs. $0 \%)$. Other effects were similar in both the groups. No drug related adverse effects were reported by Alam et $\mathrm{al}^{26}$ in their study conducted to evaluate efficacy and tolerability of racecadotril in treatment of cholera in adults. Associated symptoms of diarrhoea are abdominal pain, abdominal distension, nausea and vomiting, loss of appetite. In present study nausea and vomiting was reported in group A by 27 patients (54\%) and by 25 patients in group B (52\%). Salazar et $\mathrm{al}^{20}$ study also showed similar results in which seventy boys vomited sometime during treatment, 35 (51\%) in the racecadotril group and 35 (52 percent) in the placebo group. Baumer et $\mathrm{al}^{23}$ in their study found that the frequency of symptoms associated with diarrhoea remaining after two weeks were halved.

Using visual analogue scales, it was found that racecadotril treatment was found more effective than placebo by (both patients and investigators). Abdominal distension was also noted during the study. Three patients (6\%) from each group reported abdominal distension. Similar results were shown in a study by Hamza et $\mathrm{l}^{22}$ in which $5.6 \%$ patients on racecadotril suffered from abdominal distension as compared to $18.2 \%$ in placebo group. Abdominal pain was complained of by 6 patients $(12 \%)$ in group $A$ and by 5 patients $(10 \%)$ in group B, which is not significant statistically. Almost all the studies done so far have documented that abdominal pain was not significantly different in racecadotril group as compared to placebo, loperamide or any other drug. Loperamide and diphenoxylate-atropine combination are other drugs used for diarrhoeal treatment. Since these are mu-receptor agonists and decrease intestinal transit time, stagnation of fluid and electrolytes occur in gastrointestinal tract which is an undesired effect leading to bacterial overgrowth, abdominal distension and constipation.

Since racecadotril also potentiates endogenous opioids in intestinal mucosa, it was pertinent to study rebound constipation in racecadotril treated patients. Racecadotril has a different mechanism of action. It inhibits enkephalinase and augments the concentration of enkephalins which acts on delta receptors and by decreasing chloride secretion lead to antisecretory effect. Racecadotril has no antimotility effect and hence there is no intestinal transit delay as compared to placebo as shown by Bergman et al.27 Bergman et al ${ }^{27}$ studied 
the effect of racecadotril on intestinal motility in 12 healthy volunteers.

Orocaecal transit time was evaluated using sulphasalazine/sulphapyridine method and colonic transit times using radio-opaque and it was found that there was no significant modification in transit time linked to racecadotril treatment. In present study rebound effect was seen in 3 patients (6\%) in group A and 2 patients (4\%) in group B, which is not statistically different. As compared to loperamide racecadotril produced rebound constipation in significantly less number of subjects. In a study by Vetel et al ${ }^{28}$ rebound constipation was observed in $9.8 \%$ of subjects on racecadotril and $18.9 \%$ of subjects on loperamide treatment. It was concluded that racecadotril is more safe and tolerable than loperamide and is effective in resolving the symptoms associated with diarrhoea. Similar results were reported in other studies by Roge et al,29 Prado et al ${ }^{30}$ and Wang et al. ${ }^{25}$

\section{CONCLUSION}

Based upon the findings in the present study, it is therefore concluded that racecadotril was found to be as safe and tolerable as placebo. So far only a small number of clinical trials have been conducted and better structured trials are necessary before racecadotril can be recommended for treatment of diarrhoea.

\section{REFERENCES}

1. Sprinz H. Pathogenesis of intestinal infections. Arch Pathol 1969;87(6):556-62.

2. WHO. Health situation in south east Asia. Vol III, 20012004. 1999.

3. National Family Health Survey NFHS-2, 1998-99. Chapter 6 , mortality, morbidity and immunization, International institute of population sciences, Mumbai, India. 2000:178-235.

4. Govt of India. National child survival and safe motherhood programme, MCH division department of family welfare, ministry of health and family welfare, New Delhi 1994.

5. UNICEF. Assignment children No. 61/62, 1983.

6. Fricker J. Putting an end to diarrhoeal diseases. Children in the tropics 1993;204:1-66.

7. Bulletin WHO 1993;61:252.

8. Field M. Intestinal ion transport and pathophysiology of diarrhoea. J Clin Invest 2003;111(7):931-43.

9. Christie AB. Infectious diseases: epidemiology and clinical practice. $3^{\text {rd }}$ edn. Edinburg, Churchill Livingstone 1980.

10. Bhandari N, Bhan MK, Sazawal S. Mortality associated with acute watery diarrhea, dysentery and persistent diarrhea in rural north India. Acta Paediatr 1992;81(Suppl 381):3-6.

11. Farthing MJ. Novel targets for the control of secretory diarrhoea. Gut 2002;50(Suppl 3):III15-8.

12. WHO, UNICEF, UNFPA. Maternal mortality in 2000. Estimates developed by WHO, UNICEF, UNFPA, Geneva, 2004.

13. De S. Oral fluid therapy for cholera and non-choleric diarrhea in children. J Commun Dis 1975;7:124-8.
14. Farthing MJG. Dehydration and rehydration in children. In: Arnaud MJ, edr. Hydration throughout life. Paris: John Libbey Eurotext 1998:159-75.

15. Huang JS, Bourvaros A, Lee JW, et al. Efficacy of probiotic use in acute diarrhoea in children: a meta analysis. Diag Dis Sci 2002;47(11):2625-34.

16. Schiller LR, Santa ACA, Morawski SG, et al. Mechanism of antidiarrhoeal effect of loperamide. Gastroenterology 1984;86(6):1475-80.

17. DuPont HL, Hornick RB. Adverse effects of lomotil therapy in Shigellosis. JAMA 1973;226(13):1525-8.

18. Brown JW. Toxic megacolon associated with loperamide therapy. JAMA 1979;241(5):501-2.

19. Primi MP, Burno L, Baumer $\mathrm{P}$, et al. Racecadotril demonstrates intestinal antisecretory activity in vivo. Aliment Pharmacol Ther 1999;13(Suppl 6):63-7.

20. Salazar-Lindo E, Santisteban-Pouce J, Chea-Woo E, et al. Racecadotril in treatment of acute watery diarrhoea in children. N Eng J Med 2000;343(7):463-7.

21. WHO. Assess and classify the sick child age 2 months upto 5 years in Handbook of Integrated management of childhood illness. WHO 2005:31-8.

22. Hamza H, Khalifa BH, Baumer P, et al. Racecadotril versus placebo in the treatment of acute diarrhoea in adults. Aliment Pharmacol Ther 1999;13(Suppl 6):15-9.

23. Baumer P, Dorval DE, Bertrand J, et al. Effects of acetorphan, an enkephalinase inhibitor, on experimental and acute diarrhoea. Gut 1992;33(6):753-8.

24. Cezard JP, Duhamel JF, Meyer M, et al. Efficacy and tolerability of racecadotril in acute diarrhoea in children. Gastroenterol 2001;120(4):799-805.

25. Wang HH, Shieh MJ, Liao KF, et al. A blind, randomized comparison of racecadotril and loperamide for stopping acute diarrhea in adults. World J Gastroenterol 2005;11(10):1540-3.

26. Alam $\mathrm{NH}$, Ashraf $\mathrm{H}$, Khan WA, et al. Efficacy and tolerability of racecadotril in the treatment of cholera in adults: a double blind, randomized, controlled clinical trial. Gut 2003;52(10):1419-23.

27. Bergman JF, Chaussade S, Couturier D, et al. Effects of acetorphan, an antidiarrhoeal enkephalinase inhibitor on oro-caecal and colonic transit times in healthy volunteers. Aliment Pharmacol Ther 1992;6(3):305-13.

28. Vetel JM, Berard H, Fretault N, et al. Comparison of racecadotril and loperamide in adults with acute diarrhoea. Aliment Pharmacol Ther 1999;13(Suppl 6):216.

29. Roge J, Baumer P, Berard H, et al. The enkephalinase inhibitor acetorphan in acute diarrhoea. A double blind, controlled clinical trial versus loperamide. Scand J Gastroenterol 1993;28(4):352-4.

30. Prado D. Global adult racecadotril study group. A multinational comparison of racecadotril and loperamide in the treatment of acute watery diarrhoea in adults. Scand J Gastroenterol 2002;37(6):656-61. 